$\xi_{p}$

\title{
Measurements of Mobile Signal Received Power Level at Ringlet, Cameron Highland, Malaysia
}

\author{
S.H. Suliman ${ }^{1 *}$, W. Hashim ${ }^{2}$, A.F. Ismail ${ }^{3}$, M.A. Zakariya ${ }^{4}$ A.S. Yahya ${ }^{5}$, M.S. Sauti ${ }^{6}$ \\ ${ }^{I}$ Institute of Informatics \& Computing in Energy - Universiti Tenaga Nasional, \\ ${ }^{2}$ Dept. of Elec. \& Com. Eng., Int. Islamic University Malaysia, ${ }^{3}$ Universiti Teknologi Petronas, ${ }^{4}$ TNB IT Sdn Bhd \\ *Corresponding Author E mail: sitihusna@ uniten.edu.my
}

\begin{abstract}
Tenaga Nasional, the electric utility company in Peninsular Malaysia have been installing electronic meters that can establish wireless connectivity over the mobile phone network since 2005. Several locations including Ringlet, Cameron Highland have been pointed out as having difficulties in establishing a stable connection to the national main server. Empirical investigations had been carried out to determine the availability of service coverage and the associated signal received power levels at the said location. The findings are reported in this article. The outcomes from the measurement campaign were used to deduce the likely solution that is capable of establishing a more reliable link. Field trials involving installations of high-gain antennas and signal boosters as potential solutions were also carried out at selected sites within the district. It is the objective of the study to develop a total solution that can ultimately address the communication issue.
\end{abstract}

Keywords: Mobile phone network, signal measurement, coverage, received power level

\section{Introduction}

Automated Meter Reading (AMR) system is the technology currently deployed by Tenaga Nasional for measuring energy usage at a particular site. The system can autonomously relay the information to the Tenaga Nasional's central billing server. AMR is also claimed to be able to offer greater accuracy and heightened convenience compare to a traditional meter. This is because the system can automatically transmit digital readings to connected devices hence relieving Tenaga Nasional the burden of manual meter reading [1]-[4]. In the last few years, automatic reading of utility meter has been claimed as reaching its maturity. It is now considered as either the first step on its way towards the establishment of smart grid, or as one of the fundamental components in an existing smart grid. The AMR system basically eliminates various challenges posed by manual meter reading exercise that usually performed on monthly basis. Using AMR, the usage amounts can be read at arbitrary times as well as on scheduled date and time [3][5][6]. The technology allows utility providers to observe and monitor the consumption as well as modelling the consumers' behavioral patterns [7][8]. With sufficient data, reliable models can be established where it then becomes possible to identify seasonal or time-varying trends to forecast short-term and long-term consumptions or even detect frauds [9]-[11]. All these outcomes may help energy providers, distributors and reseller companies make better investment decisions and strategic planning. Despite all the advantages over the "manual reading" procedure, the data from AMR had been occasionally reported as "missing" and one of the possible causes is due to communication faults [12][13].

All communication devices that are wirelessly connected are vulnerable to risks such as lost connectivity, call drop-outs and out- of-coverage signaling, especially when collecting real-time data in a short period of interval [14]. There are locations where it can be a real challenge in ensuring good connectivity at all times especially at the edge of the cell coverage. This can be even more challenging when the AMR system relies on just one dedicated single connection since should anything happen to this network, the AMR meter can only resume operation once the network is back to normal [15]. A previous study highlighted that establishing reliable communication link can be a real challenge at locations where AMR systems are installed [16]. The locations were grouped into four typical localities, namely new industrial development, single network connection, rural area or smaller city, and geographical terrain.

AMR systems installed at Ringlet, Cameron Highland, a township in the state of Pahang, have been reported as experiencing missed data updates to the Tenaga Nasional's central server. Ringlet is the first town of the resort destination Cameron Highland located approximately $200 \mathrm{~km}$ from Kuala Lumpur. A team was assembled to investigate the likely causes of the connection predicaments. Among the objectives were to explore and to establish the cellular communication coverage available at the said highland areas. The investigation was divided into two-part analyses. The first part involved measuring and comparing the mobile signal received power levels. The signals after all have to propagate through areas covered with dense foliage. The Anritsu MS 2711 handheld spectrum analyzer was used to determine the signals' amplitudes. There are four test sites that were identified within the vicinity of Ringlet, Cameron Highland. The second part of the investigation was associated with the measurement of improved received power levels when high-gain antennas and signal boosters were deployed. Relevant measurement details are included in the following sections.

The contents of this article are organized as follows: Section 2 describes the background work of the study and Section 3 outlines 
system and measurement. Then followed by measurement technique, result, discussion, attempts to increase the signal received power level and conclusion; titled as section 3, 4, 5 and 6 respectively.

\section{Background}

In telecommunications, measurement of the power present in a received radio signal can also be identified as Received Signal Strength Indication (RSSI). In most cases, RSSI is used interchangeably with signal received power level. Paid subscribers of any particular communication service do expect an uninterrupted, efficient and stable connection. In the attempt of providing uninterrupted service, providers or operators must carried out the performance testing regardless of the location and its geographical terrain [17][18]. The configuration was adjusted and fine-tuned to deliver the required Quality of Service (QoS) at the initial stage of service roll-out for all areas. A lot can happen over the years where geographical terrain itself can be transformed. In recent year, various studies on signal measurement in mountainous areas and areas covered with thick foliage have been actively conducted. Explorations to understand how the vegetation plantation can affect communication range had been carried out and behavior changes of microwave signal radiation for wireless communication in this area were studied [19][20]. The findings from the measurement were used to gauge the effectiveness of Long Range (LoRa) applications in non-urban environments. Another study was also conducted to asses the efficacy of ZigBee's transmission range in the forest environment [21]. The findings showed that vegetation does affect the transmission range of wireless communication. The paper furthermore outlines an empirical study involving XBee transmission range in the forest based on RSSI values. The measurements were conducted in two different types of forests: heterogeneous tropical forest and homogeneous pine forest. The measurement results indicated a reduction of transmission range when compared to environments without trees. The RSSI measurement of a cellular network was carried out in vegetation areas to investigate how cornfield vegetation affects the signal received power level. The study concluded that the propagation of radio signals is indeed affected by vegetation and the specific effect on the propagation is very much influenced by the vegetation characteristics.

An experiment involving video streaming over a wireless channel in the presence of fading caused by the physical environment was also reported [23][24]. The study records a very poorly received video quality when streaming video file wirelessly across an agricultural area [25]. Besides foliage and vegetation, weather condition can as well affect the wireless signal quality. RSSI values were compared at varying wind speeds, dry and wet weather conditions [26]. Wet weather conditions in the studies were categorized as heavy rain, extremely heavy rain, torrential rain, and extremely torrential rain.

RSSI measurements at an open clear line of sight areas were also conducted by previous investigators [27]-[30]. The measurement was done using the NEMO handheld device as the data acquisition apparatus. The collected data were then analyzed by using the software identified as NEMO Outdoor 6 . The measurements were taken during the morning, afternoon and evening periods on three fine days [27]. Signal measurements had been acquired for urban, suburban and rural areas [28].

Based on the above-mentioned related studies, they very much substantiate the need to carry out the RSSI measurements in areas where AMR systems were reported as facing communication issues. The need for a steady and stable communication coverage is critical for locations installed with AMR devices. Ringlet, Cameron Highland is located at $4.24^{\circ} \mathrm{N}$ and $101.26^{\circ} \mathrm{E}$, with altitude above sea level of about $1400 \mathrm{~m}$. Ringlet is a unique place well known for eco-tourism where visitors can hike trails in a cool tropical rainforest. It is also known as fertile agricultural areas.

\section{System and Measurement Parameters}

The technical details involved during the measurement campaign are listed in Table 1. The measurements were intended to acquire signal received power levels or RSSI for mobile services operating in GSM900, GSM1800, UMTS and LTE frequency bands. The range of the measurements for the services mentioned involve the frequencies between $800 \mathrm{MHz}$ and $2.9 \mathrm{GHz}$. During the campaign, there were four mobile communication operators of interest, identified as Maxis, Celcom, Digi, and U Mobile. The exact frequency allocations for the different mobile service operators are as listed in Table 2. The information was published by the Malaysia Communications and Multimedia Commission (MCMC) [32]. The measurement tools for the outdoor RF signal measurement consist of a spectrum analyzer (Figure 1) and omnidirectional antenna with a gain of $2 \mathrm{dBi}$ (Figure 2).

Table 1: System Description

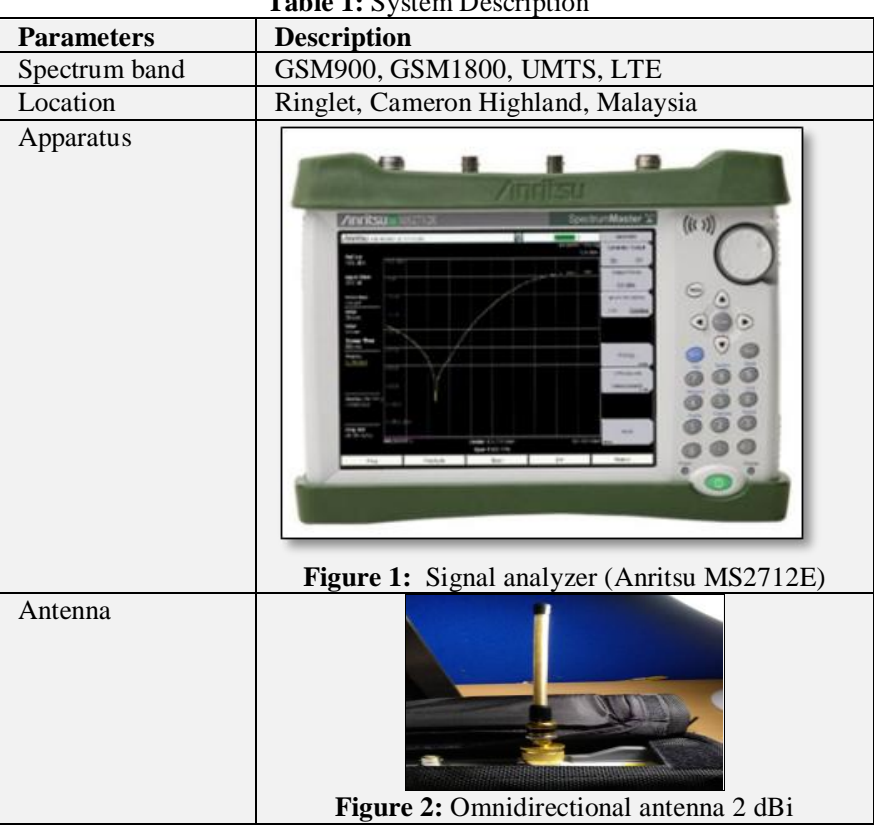

For the reference of the signal measurement, the specific frequency allocation, bandwidth, uplink and downlink frequency for different telecommunication companies are summarized in Table 2.

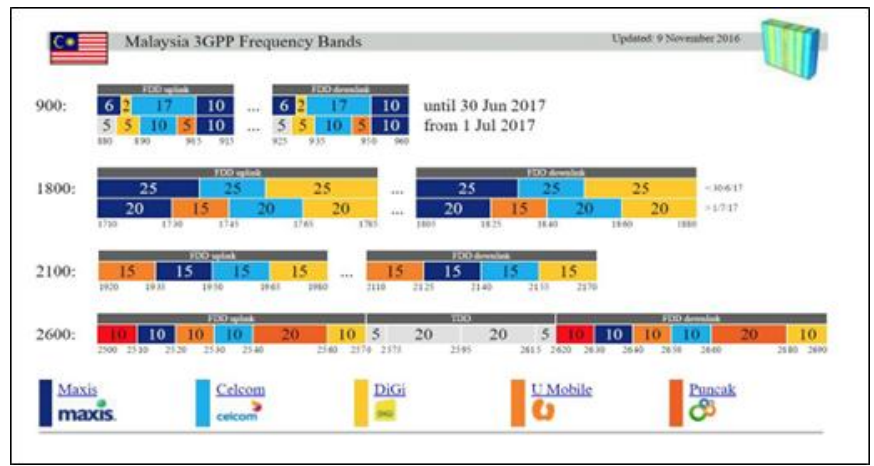

Figure 3: Spectrum Allocation

Table 2: Spectrum Allocation Table

\begin{tabular}{|c|c|c|}
\hline Technology & Uplink (MHz) & Downlink (MHz) \\
\hline \multicolumn{3}{|c|}{ Celcom } \\
\hline GSM900 & $890-900$ & $935-945$ \\
\hline GSM1800 & $1745-1765$ & $1840-1860$ \\
\hline UMTS & $1950-1965$ & $2140-2155$ \\
\hline LTE & $2530-2540$ & $2650-2660$ \\
\hline \multicolumn{3}{|c|}{ Maxis } \\
\hline GSM900 & $905-915$ & $950-960$ \\
\hline GSM1800 & $1710-1730$ & $1805-1825$ \\
\hline
\end{tabular}




\begin{tabular}{|l|l|l|}
\hline UMTS & $1935-1950$ & $2125-2140$ \\
\hline LTE & $2510-2520$ & $2630-2640$ \\
\hline \multicolumn{3}{|c|}{ Digi } \\
\hline GSM900 & $885-890$ & $930-935$ \\
\hline GSM1800 & $1765-1785$ & $1860-1880$ \\
\hline UMTS & $1965-1980$ & $2155-2170$ \\
\hline LTE & $2560-2570$ & $2680-2690$ \\
\hline \multicolumn{3}{|c|}{ U Mobile } \\
\hline GSM900 & $900-905$ & $945-950$ \\
\hline GSM1800 & $1730-1745$ & $1825-1840$ \\
\hline UMTS & $1920-1935$ & $2110-2125$ \\
\hline LTE & $2520-2530$ & $2640-2650$ \\
\hline
\end{tabular}

Table 3: Measurement data for Site Location A

\begin{tabular}{|l|l|l|}
\hline \multicolumn{3}{|c|}{ Location Coordinate: $4.414665 \mathrm{~N}, 101.384628 \mathrm{E}$} \\
\hline Signal $(\mathrm{MHz})$ & RSSI $(\mathrm{dBm})$ & Provider \\
\hline 889.700 & -30.22 & Digi GSM900 \\
\hline 895.5 & -35.00 & Celcom GSM900 \\
\hline 901 & -43.00 & U Mobile GSM900 \\
\hline 912.75 & -31.93 & Maxis GSM900 \\
\hline $1.959 \mathrm{GHz}$ & -53.13 & Celcom UMTS \\
\hline
\end{tabular}

\subsection{Measurement Procedures}

The measurements of the signal at Ringlet, a high-altitude location was conducted according to the following sequences:

a) The spectrum analyzer was set to measure any received signals starting from $800 \mathrm{MHz}$ up to $2.9 \mathrm{GHz}$

The signal strength magnitudes of all the available signals were recorded. One sample is as shown in Figure4

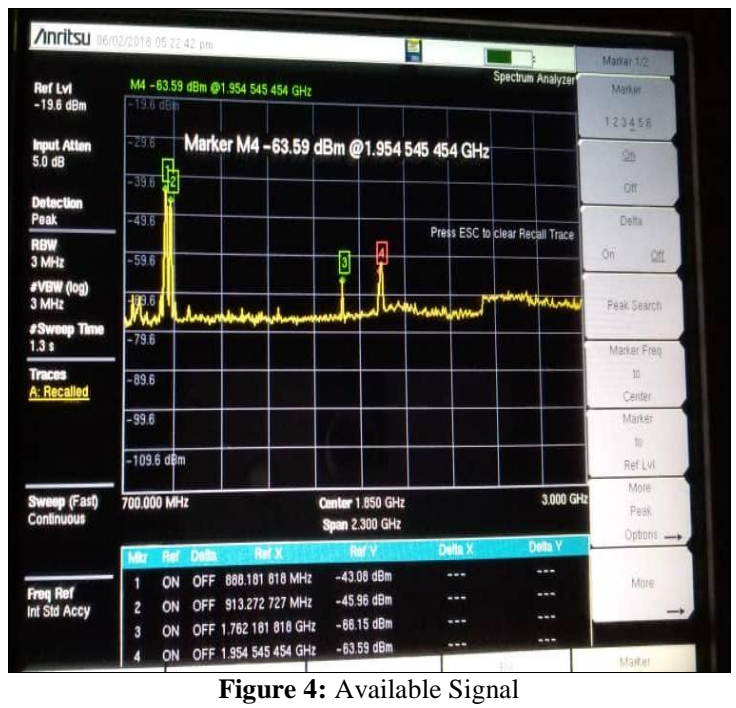

b) The mobile service providers were identified by referencing to information according to Figure 3.

c) The results of signal strength were analyzed and compared.

d) The performance of the communication channel was evaluated.

\section{Results and Discussion}

The signal received power levels at four different site locations labelled as Site Location A, B, C, and D had been identified. The magnitude and the available frequencies of the recorded data acquired during the measurement campaign are tabulated in Table 3 and graph in Figure 5 represents the comparison of signal strength. The data collected at specific sites equipped with location information using GPS can be used to verify the availability of services offered by the telecommunication operators.

It was observed that there are five active communication links that are operating at center frequencies of $889.70 \mathrm{MHz}, 895.50 \mathrm{MHz}$, $901.00 \mathrm{MHz}, 912.75 \mathrm{MHz}$, and $1.959 \mathrm{GHz}$. The corresponding RSSI signal strength levels are $-30.22 \mathrm{dBm},-35.00 \mathrm{dBm},-43.00$ $\mathrm{dBm},-31.93 \mathrm{dBm}$, and $-52.13 \mathrm{dBm}$. With reference to Table 2 , the respective service providers for the available communication channels were identified as Maxis GSM900, Celcom GSM900, U Mobile GSM900, Maxis GSM900 and Celcom UMTS. It was found that at the coordinate for Site A, the Maxis GSM900 signal has the highest signal strength level, followed by $U$ Mobile GSM900 and Celcom UMTS.

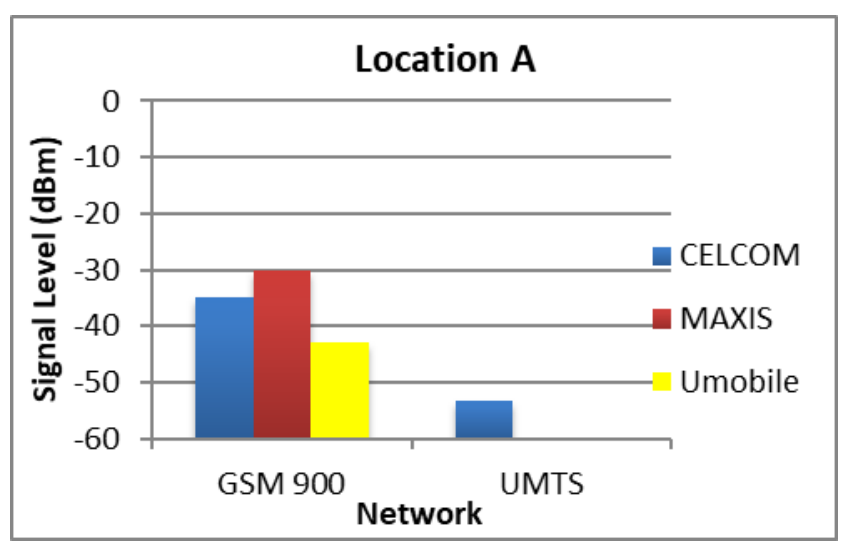

Figure 5: Graph of Location A RSSI Performance

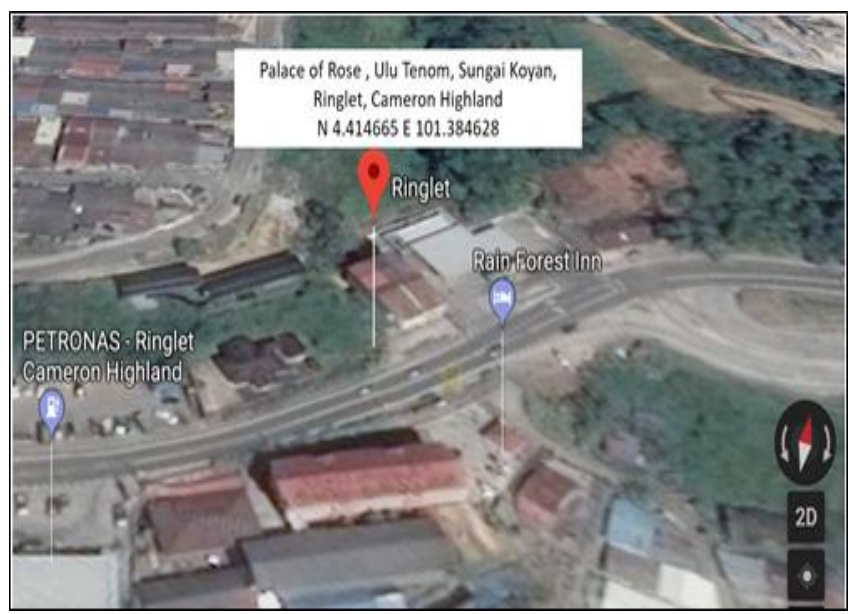

Figure 6: Geographical area of Site Location A

The location for the Site A produced using the Google Map application is shown in Figure 6. The location is situated nearby the main road, but the contour of the location is at the height of $800 \mathrm{~m}$ from the sea level. The level is lower with a deviation of $900 \mathrm{~m}$ as compared to other identified sites. There are however more obstacles such as building, big trees and a small hill that exist between the site and the base station. Based on Table 3, it can be observed that the Maxis GSM900 has the highest signal level hence can be assumed as the nearest base station

For site Location $\mathrm{B}$, there were four center frequencies detected which are $888 \mathrm{MHz}, 913 \mathrm{MHz}, 1.762 \mathrm{GHz}$, and $1.962 \mathrm{GHz}$; with a signal strength of $-43.00 \mathrm{dBm},-45.00 \mathrm{dBm},-66.15 \mathrm{dBm}$, and $61.28 \mathrm{dBm}$ respectively (Table 4 ). It can be concluded that there are only three Telco service providers offering coverage in this area, which are Digi GSM900, Maxis GSM900, Celcom GSM1800, and Celcom UMTS. The signal received power level magnitude were also lesser compared with Site Location A. It is found that Celcom UMTS signal magnitude is reduced with a deviation of $8.1 \mathrm{~dB}$ from $-53.13 \mathrm{dBm}$ to $-61.28 \mathrm{dBm}$. Meanwhile, the Maxis GSM900 signal dropped with a deviation of $13.3 \mathrm{~dB}$ from $-31.3 \mathrm{dBm}$ to $-45.00 \mathrm{dBm}$. It is also found that the Digi GSM900 signal was measured at this site with center frequency of $888 \mathrm{MHz}$ and a signal level of $-43 \mathrm{dBm}$. Figure 7 shows the graphical representations of the RSSI performance. 
Table 4: Measurement data for Site Location B

\begin{tabular}{|l|l|l|}
\hline \multicolumn{3}{|c|}{ Location Coordinate: $4.402170 \mathrm{~N}, 101.454539 \mathrm{E}$} \\
\hline Signal (MHz) & RSSI $(\mathrm{dBm})$ & Provider \\
\hline 888 & -43.00 & Digi GSM900 \\
\hline 913 & -45.00 & Maxis GSM900 \\
\hline 1.762 & -66.15 & Celcom GSM1800 \\
\hline 1.962 & -61.28 & Celcom UMTS \\
\hline
\end{tabular}

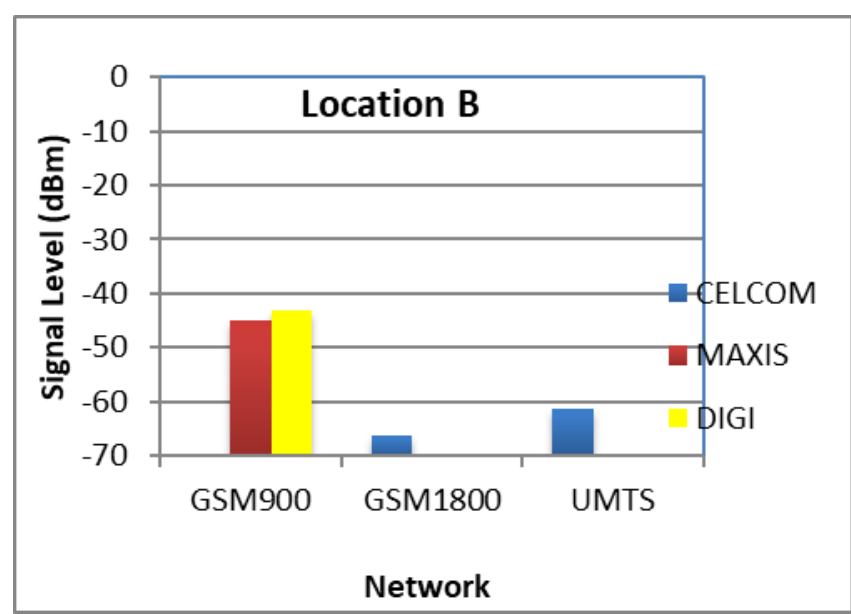

Figure 7: Graph of Location B RSSI Performance

The surrounding geographical infrastructures for Site Location B are shown in Figure 8. The site is located at the top contour of a hill, which is at approximately $1260 \mathrm{~m}$ with reference to the sea level. The site is located at a distance of $1200 \mathrm{~m}$ from the roadway access of Brinchang road. As one can be observed, the site is located in an area surrounded by forests. The base stations for the mobile phone services are located at Lembah Bertam, which is at about $14.6 \mathrm{~km}$ distance away from location A.

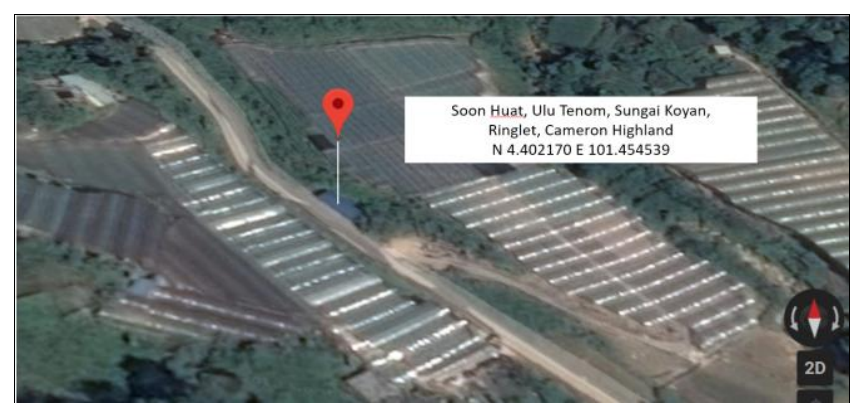

Figure 8: Geographical area of Site Location B

Measurements were further carried out at site Location C. The site is at the Ng KC Farm in Ulu Tenom. At the location, the only received signal is from a nearby private $\mathrm{Wi}$-Fi router. The center frequency is $2436 \mathrm{MHz}$ with received power level of $-43.81 \mathrm{dBm}$, as listed in Table 5 and plotted in graph as shown in Figure 9. There is no Telco signal detected by the spectrum analyzer. The site is situated at the height of $1350 \mathrm{~m}$ above sea level and its location is far from the main road. It can be stipulated that the site experiences zero received signal from the base station due to obstacles blocking the propagation path. It can be visually observed that there are several building structures in between the site and the desired base station as shown in Figure 10.

Table 5: Measurement data for Site Location C

\begin{tabular}{|l|l|l|}
\hline \multicolumn{3}{|c|}{ Location Coordinate: $4.4211 \mathrm{~N}, 101.44535 \mathrm{E}$} \\
\hline \multicolumn{3}{|c|}{ Available Coverage } \\
\hline Signal $(\mathrm{MHz})$ & RSSI $(\mathrm{dBm})$ & Provider \\
\hline 2436.5 & -43.81 & - \\
\hline
\end{tabular}

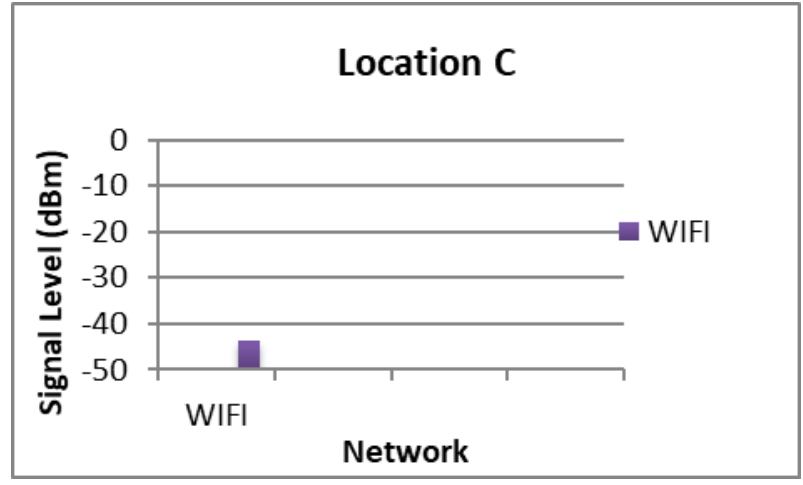

Figure 9: Graph of Location C

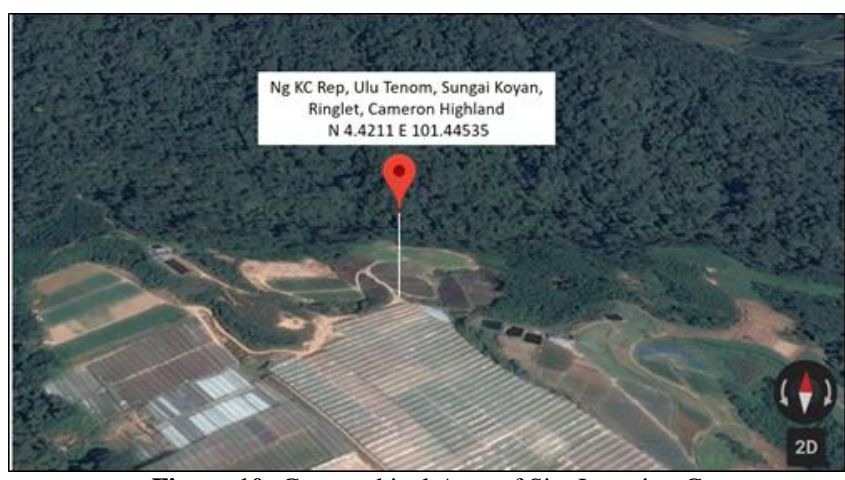

Figure 10: Geographical Area of Site Location C

The final location was identified as the Site Location D. At the location, Telco signals with center frequencies of $913 \mathrm{MHz}, 1.958$ $\mathrm{MHz}$, and $1.745 \mathrm{GHz}$ were detected. The measured signal received power levels were $-22 \mathrm{dBm},-54 \mathrm{dBm}$ and $-38 \mathrm{dBm}$ for the said frequencies (Table 6). It was found that the site experiences the strongest signals as compared to previous Sites Locations A, B and C. It can be assumed that the Celcom UMTS, Celcom GSM1800 and Maxis GSM900 can establish a good communication link between the site and the base station. The Maxis GSM had the highest signal received power level according to the measured data, followed by Celcom GSM900 and Celcom UMTS. Figure 11 shows the graphical representation of the signal performance at Site Location C.

Table 6: Measurement data for Site Location D

\begin{tabular}{|l|l|l|}
\hline \multicolumn{3}{|c|}{ Location Coordinate: $4.408840 \mathrm{~N}, 101.450637 \mathrm{E}$} \\
\hline Signal $(\mathrm{MHz})$ & RSSI $(\mathrm{dBm})$ & Provider \\
\hline 913 & -22 & Maxis GSM \\
\hline 1.958 & -54 & Celcom 3G \\
\hline 1.745 & -38 & Celcom 2G \\
\hline
\end{tabular}

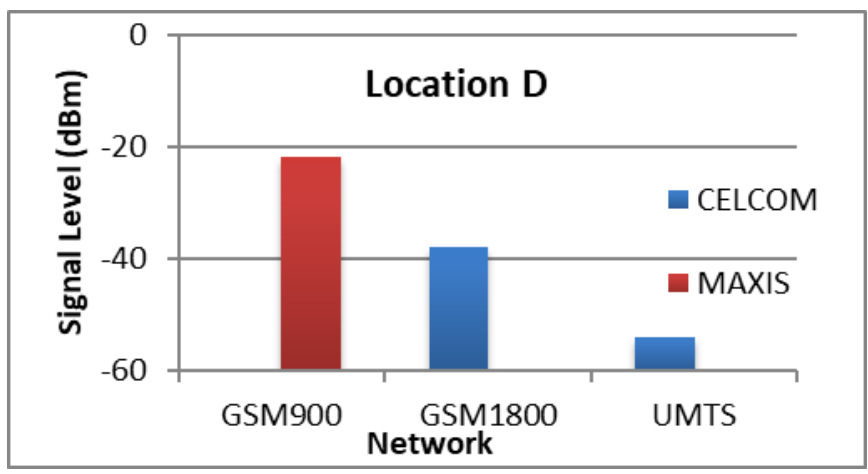

Figure 11: Graph of Location D

Figure 12 shows the geographical surrounding infrastructure of Site Location D. It is depicted that the site is situated in an open area with only a small plantation surrounding the site station. As a result, the site is able to receive Telco signals from all angles, 
radiated in the surrounding. There is no obstacle or blockage to attenuate the transmit signal from the base station to the spectrum analyzer.

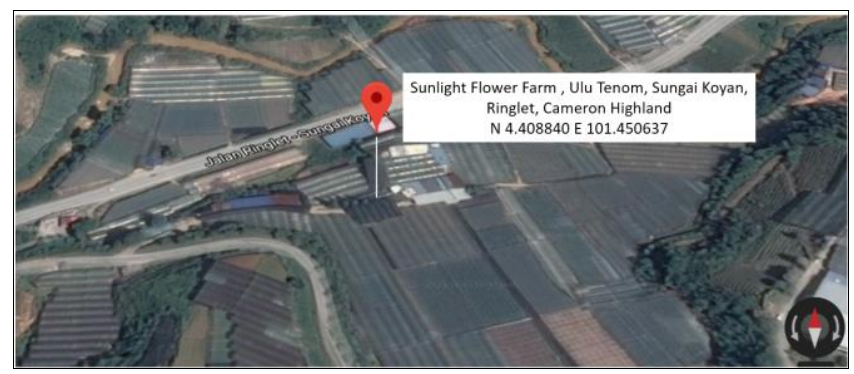

Figure 12: Geographical area of Site Location D

\section{Increasing the Signal Received Power Level}

After evaluating the available connectivity selections based on the measured data, several options were explored in the attempt to increase the signal received power level. Installing new mobile phone base station infrastructure might after all, be the best solution to overcome the issue. However, new infrastructure means extra cost and it will be a great challenge to justify the return on investment. The installation on a geographical terrain such as the top of the hill can certainly pose an engineering test [33]. The service provider may, in any case, refuse to proceed unless enough revenue generation can be assured. Two potential solutions were explored in the hope to resolve the communication link issue. These involved deployments of a high-gain antenna and the setting up of a signal booster. Site Location $\mathrm{C}$ was selected as the trial sites for the proposed configuration.

Configuration 1: Installation of a directional high-gain antenna. As part of the experimental setup, a directional high-gain antenna $9 \mathrm{dBi}$ was deployed to replace the $2 \mathrm{dBi}$, used previously. The installation was as shown in Figure 13.

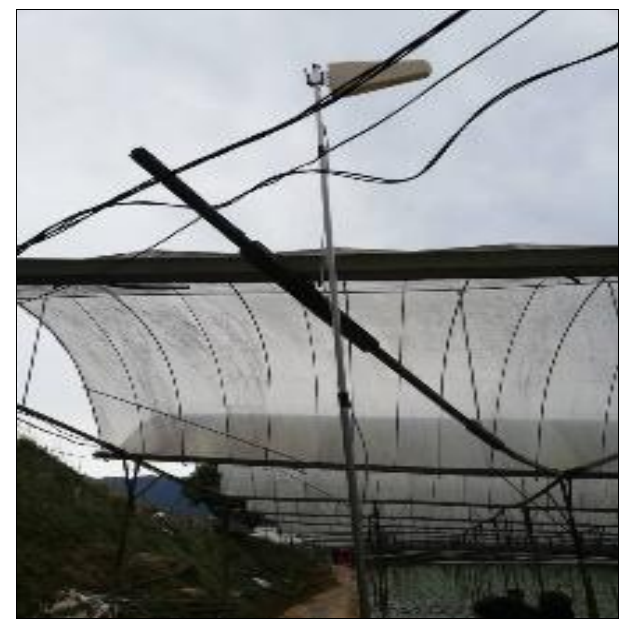

Figure 13: Directional High Gain Antenna

The findings are presented in Table 7. It was ascertained that higher signal received power level readings can be achieved and graph in Figure 14 represents the data.

Table 7: Available Coverage for the Site C

\begin{tabular}{|l|l|l|}
\hline \multicolumn{3}{|c|}{ Location Coordinate: $4.414665 \mathrm{~N}, 101.384628 \mathrm{E}$} \\
\hline \multicolumn{3}{|c|}{ Improved Available Coverage } \\
\hline Signal $(\mathrm{MHz})$ & RSSI $(\mathrm{dBm})$ & Provider \\
\hline 889 & -20 & Digi GSM900 \\
\hline 1.752 & -34 & Celcom GSM1800 \\
\hline 1.959 & -45 & Celcom UMTS \\
\hline 912 & -30 & Maxis GSM900 \\
\hline 1.758 & -38 & Celcom GSM1800 \\
\hline 1.729 & -39 & Maxis GSM1800 \\
\hline
\end{tabular}

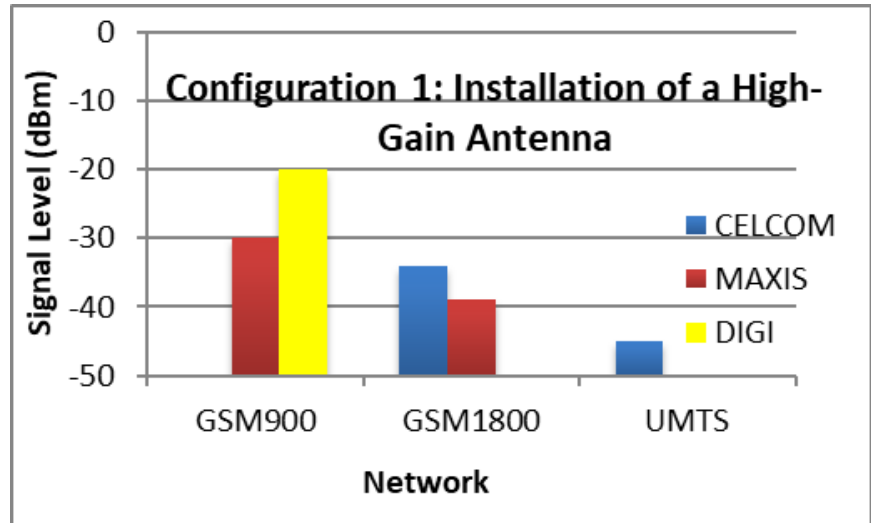

Figure 14: Graph of Configuration 1

Configuration 2: Installation of a directional high-gain antenna coupled with a Signal Booster.

For the setup, a directional antenna that was positioned at an open space area was then connected to a signal booster. All components were connected with a high-quality cable to ensure minimal attenuation loss. The experiment setup is shown in Figure 15.
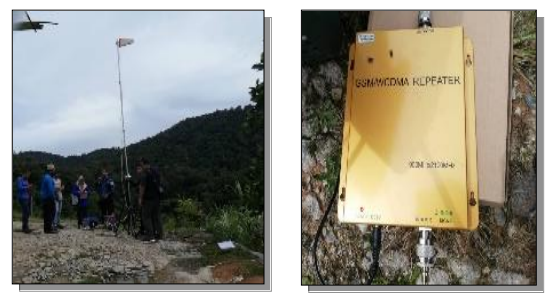

Figure 15: Experiment Setup for Signal Booster

The results are presented in Table 8 and illustrated in graph as shown in Figure 16. It was discovered that several additional available signals were detected when the directional antenna was set to face direction of $60^{\circ}$ from north.

Table 8: Available Coverage for Site Location C

\begin{tabular}{|l|l|l|}
\hline \multicolumn{3}{|c|}{ Location Coordinate: $4.4211 \mathrm{~N}, 101.44535 \mathrm{E}$} \\
\hline \multicolumn{3}{|c|}{ Improved Available Coverage } \\
\hline Signal (MHz) & RSSI $(\mathrm{dBm})$ & Provider \\
\hline 2143.25 & -19.36 & Celcom UMTS \\
\hline 1.959 & -49.65 & Celcom UMTS \\
\hline 1.758 & -24 & Celcom GSM1800 \\
\hline 1.712 & -38.07 & Maxis GSM1800 \\
\hline 958.75 & -48.26 & Maxis GSM900 \\
\hline 930 & -47.54 & Digi GSM900 \\
\hline 912.75 & -23.24 & Maxis GSM900 \\
\hline 907 & -25.73 & Maxis GSM900 \\
\hline
\end{tabular}

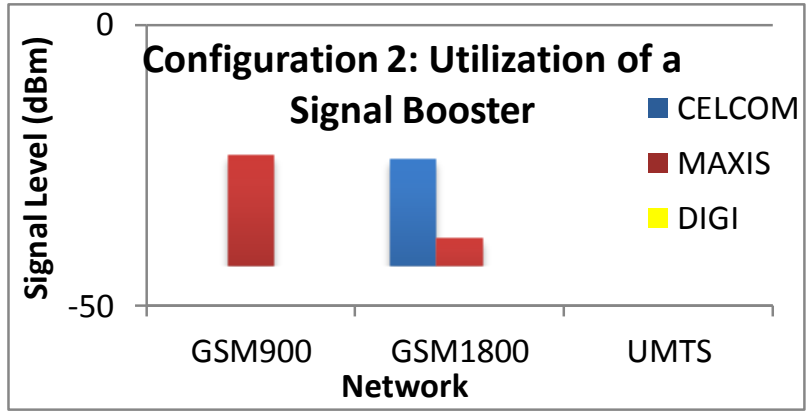

Figure 16: Graph of Configuration 2

\section{Conclusion}

The signal received power level measurements had been conducted at four specific AMR locations in Ringlet, Cameron Highland. Signal coverage of Telco services; namely, Celcom, Maxis and 
Digi had been empirically determined. It was obvious that different locations received varying signal received power levels. The power levels might even be below the minimum threshold of a communication setup. The proposed solutions outlined in this article may be deployed to overcome the communication issue with minimum investment. The findings also suggest that having connectivity to more than one telecommunication service provider can also be a potential solution to achieving a more reliable connection. An AMR system with dual or triple sim can perhaps reduce the likelihood of intermittent and connection instability especially when the device can autonomously select the best connection for data transmission. UMTS and LTE services offer higher speed connectivity compared to current GSM option. The coverage area of UMTS and LTE have been growing exponentially over the years and about to match the area currently serviced by GSM. It is now perhaps the right time for Tenaga Nasional to upgrade the AMR connection to include the latest LTE and UMTS services rather than solely relying on GSM, which will eventually be phased out very soon.

\section{Acknowledgement}

We would like to state our utmost gratitude to the TNB for sponsoring our field work project based on TNB seeding fund grant $\mathrm{U}$ TI-RD-17-04 and UNITEN internal grant J-510050740 for financing the publication fee.

\section{References}

[1] D. Of, A. N. Intelligent, G. S. M. Based, and A. Meter, "Icmere2015-Pi-266 Development of an Intelligent Gsm Based Automatic Meter," Proc. Int. Conf. Mech. Eng. Renew. Energy 2015, vol. 2015, pp. 26-29, 2015.

[2] R. G. Sarangle, U. Pandit, K. Prof, and J. Modi, "Gsm Based Power Meter Reading,” Int. J. Adv. Res. Comput. Eng. Technol., vol. 1, no. 4, pp. 273-279, 2012.

[3] K. Ashna and S. N. George, "GSM based automatic energy meter reading system with instant billing," Proc. - 2013 IEEE Int. Multi Conf. Autom. Comput. Control. Commun. Compress. Sensing, iMac4s 2013, pp. 65-71, 2013.

[4] H. Mujahid, K. Irfan, K. Jafar, and K. Juned, "Comprehensive Monitoring of Energy Meter,” Int. J. Res. Sci. Eng. Spec., no. 7, 2017.

[5] I. Christopher et al., "Data Collector For An Automated Meter Reading System," United States Pat., 2007.

[6] M. Shinwari, A. Youssef, and W. Hamouda, "A Water-Filling Based Scheduling Algorithm for the Smart Grid," Smart Grid, IEEE Trans., vol. 3, no. 2, pp. 710-719, 2012.

[7] T. Chen, A. Mutanen, P. Jarventausta, and H. Koivisto, "Change detection of electric customer behavior based on AMR measurements," 2015 IEEE Eindhoven PowerTech, PowerTech 2015, no. January, 2015.

[8] I. Conference and E. D. Frankfurt, "21 st International Conference on Electricity Distribution Paper 0277 CUSTOMER CLASSIFICATION AND LOAD PROFILING BASED ON AMR 21 st International Conference on Electricity Distribution Frankfurt 6-9 June 2011 Paper 0277," no. 0277, pp. 6-9, 2011.

[9] P. Valtonen, S. Honkapuro, and J. Partanen, "Improving short-term load forecast acuracy by utilizing smart metering," CIRED Work., no. June, pp. 1-4, 2010.

[10] D. Alahakoon and X. Yu, "Smart Electricity Meter Data Intelligence for Future Energy Systems: A Survey," IEEE Trans. Ind. Informatics, vol. 12, no. 1, pp. 425-436, 2016.

[11] M. Ghofrani, M. Hassanzadeh, M. Etezadi-Amoli, and M. S. Fadali, "Smart meter based short-term load forecasting for residential customers," NAPS 2011 - 43rd North Am. Power Symp., no. October 2014, 2011.

[12] T. Cemgil, B. Kurutmaz, A. Cezayirli, E. Bingol, and S. Sener, "Interpolation and fraud detection on data collected by automatic meter reading," 2017 5th Int. Istanbul Smart Grid Cities Congr. Fair, no. 1 , pp. 51-55, 2017.

[13] A. Z. Morch, I. Graabak, and N. Feilberg, "Results of Monitoring of AMR Systems in Norway: Analysis of Metered Data and
Definition of the Performance Parameters," 20th Int. Conf. Electr. Distrib., no. 0465 pp. 8-11, 2009.

[14] V. C. Güngör et al., "Smart grid technologies: Communication technologies and standards," IEEE Trans. Ind. Informatics, vol. 7, no. 4, pp. 529-539, 2011.

[15] I. J. C. Johnson, "SYSTEM FOR UTILITY METER COMMUNICATIONS USING A SINGLE RF FREQUENCY," United States Pat., no. 5914673, 1999.

[16] S. H. Suliman, W. Hashim, A. F. Ismail, A. S. Yahya, M. H. Khairolanuar, and U. T. Nasional, "Wireless Connectivity Predicaments in GSM-based AMR System: An Empirical Study," no. $x, 2017$.

[17] C. Delhi, R. Quality, and R. Quality, "Analysis of the Network Performance of the Telecom Service Providers in Mumbai and Delhi," 2015.

[18] M. A. Salawu, "On the Practical Assessment of Signal Strength of GSM Network Service Providers," Glob. J. Sci. Front. Res. A Phys. Sp. Sci., vol. 14, no. 1, 2013

[19] O. Iova et al., "LoRa from the City to the Mountains: Exploration of Hardware and Environmental Factors," Proc. 2nd Int. Work. New Wirel. Commun. Paradig. Internet Things, pp. 20-22, 2017.

[20] K. A. Ahmad, M. S. Salleh, J. D. Segaran, and F. R. Hashim, "Impact of foliage on LoRa $433 \mathrm{MHz}$ propagation in tropical environment," AIP Conf. Proc., vol. 1930, pp. 1-7, 2018.

[21] Iswandi, H. T. Nastiti, I. E. Praditya, and I. W. Mustika, "Evaluation of XBee-Pro transmission range for Wireless Sensor Network's node under forested environments based on Received Signal Strength Indicator (RSSI)," in Proceedings - 2016 2nd International Conference on Science and Technology-Computer, ICST 2016, 2017, pp. 56-60.

[22] K. P. Hunt, S. Member, J. J. Niemeier, L. K. Cunha, and A. Kruger, "to Monitor Vegetation Characteristics," 346 IEEE Geosci. Remote Sens. Lett., vol. 8, no. 2, pp. 346-349, 2011

[23] M. F. Ramli et al., "The study of vegetation effect on wireless streaming video for agricultural monitoring," J. Teknol., vol. 76, no 12 , pp. 53-58, 2015.

[24] M. Li, M. Claypool, and R. Kinicki, "Playout buffer and rate optimization for streaming over IEEE 802.11 wireless networks," ACM Trans. Multimed. Comput. Commun. Appl., vol. 5, no. 3, pp. 1-25, 2009.

[25] A. Harun et al., "Comparative performance analysis of wireless RSSI in wireless sensor networks motes in tropical mixed-crop precision farm," Proc. - 3rd Int. Conf. Intell. Syst. Model. Simulation, ISMS 2012, no. July, pp. 606-610, 2012.

[26] S. H. Fang and Y. H. S. Yang, "The Impact of Weather Condition on Radio-Based Distance Estimation: A Case Study in GSM Networks with Mobile Measurements," IEEE Trans. Veh. Technol., vol. 65 , no. 8, pp. 6444-6453, 2016.

[27] M. A. Zainali et al., "Drive test measurement be tween Maxis $2 \mathrm{G}$ and 3G networks in Uitm Shah Alam campus," Proceeding - 2013 IEEE Student Conf. Res. Dev. SCOReD 2013, no. December, pp 392-397, 2015.

[28] T. Yuwono and F. Ferdiyanto, "Measurement and analysis of 3G WCDMA network performance case study: Yogyakarta Indonesia," 2015 4th Int. Conf. Instrumentation, Commun. Inf. Technol. Biomed. Eng., pp. 294-297, 2015.

[29] A. F. De Toledo, A. M. D. Turkmani, and J. D. Parsons, "Estimating coverage of radio transmission into and within buildings at 900, 1800, and $2300 \mathrm{MHz}$," IEEE Pers. Commun., vol. 5 , no. 2 , pp. 40-47, 1998.

[30] E. Oluwajobi and F. Idowu, "Comparative Analysis of The Received Signal Strength Measurement of GSM Network in Owo , Ondo State Nigeria,” Int. J. Emerg. Technol. Adv. Eng., vol. 5, no. 7, pp. 305-311, 2015.1] S. A. Gbadamosi, A. M. Aibinu, E. Nonwuka, and O. K. Ugweje, "Towards independent measurement of End to End Bit Error Rate in GSM network," Proc. 11th Int. Conf. Electron. Comput. Comput. ICECCO 2014, pp. 1-4, 2014.

[32] "Malaysian Communications And Multimedia Commission (MCMC) | Suruhanjaya Komunikasi dan Multimedia Malaysia (SKMM) - Spectrum Allocation." [Online]. Available: https://www.mcmc.gov.my/spectrum/spectrum-allocationlist/spectrum-allocation. [Accessed: 03-Jul-2018].

[33] P. P. Parikh, M. G. Kanabar, and T. S. Sidhu, "Opportunities and challenges of wireless communication technologies for smart grid applications," IEEE PES Gen. Meet., no. Cc, pp. 1-7, 2010. 